\title{
Influence of the Vertical Earthquake Component on the Shear Vibration of Buildings on Sliding Foundations
}

\author{
Ibrakhim Mirzaev ${ }^{1 *}$, Anvar Yuvmitov ${ }^{1}$, Malikjon Turdiev ${ }^{2}$ and Jakhongir Shomurodov ${ }^{2}$ \\ ${ }^{1}$ Academy of Science of the Republic of Uzbekistan Institute of Mechanics and Seismic Stability of \\ Structures named after M.T. Urazbaev, Tashkent, Uzbekistan \\ ${ }^{2}$ Tashkent State Transport University, Tashkent, Uzbekistan
}

\begin{abstract}
The paper studied the vibrations of the buildings on the sliding foundation with dry friction under the action of real earthquakes at the intensity of 8 and 9 on the MSK-64 scale. It was developed a unique algorithm for calculating the displacements, velocities, accelerations, and shear forces resulting from the simultaneous action of the horizontal and vertical components of the seismogram record. It was studied four-story and nine-story buildings under the set of the three earthquake records. It was shown that the use of a sliding foundation does not always lead to a significant reduction in the shear force on the building floors and that the vertical component of the seismic effect has a significant influence on the shear vibration of the building.
\end{abstract}

\section{Introduction}

In recent decades, various measures have been taken in countries worldwide to protect the buildings and structures from the unfortunate effects of the strong earthquakes [1-6]. One effective method of the seismic isolation is the sliding foundation using a layer of fluoroplastic $[2,3]$.

In [4], a study of seismic isolation in the pipeline system in the form of Teflon interlayer was carried out. In the numerical studies, the seismic isolation was modeled as dry friction, but the dry friction model is replaced by an "Ideal elastoplastic body" model during implementation.

In [5], a study of seismic vibrations of the multi-story building with sliding support is given. The condition of the joint motion used the force of inertia of the whole building. In [6], the results of studies of the high-rise building with an application of the seismic isolation in the form of the steel- laminated rubber bearings are given.

In [11], the results of measured processing accelerations during the earthquakes of the three buildings constructed in Almaty in 1989 are described. These three buildings had the same above-ground foundation (9-storey large-panel in 158-series houses) but the different foundations: conventional strip, kinematic, and supports with fluoroplastic layers. The contact surfaces with fluoroplastic have inclined planes. On August 16, 2014, an earthquake

*Corresponding author: ibrakhim.mir@mail.ru 
was recorded with its epicentre located $41 \mathrm{~km}$ east of Almaty. Underground shocks were felt in Almaty at 4 - 5 points on MSK-64 scale. The maximum values of spectral coefficient $\beta$ for seismically isolated buildings at the 9th-floor level are less than those for the analogue building: for buildings with fluoroplastic layers - on $11 \%$, for buildings with kinematic foundations - on $63 \%$. When selecting the optimal value of dry friction coefficient to reduce the earthquake effect on buildings with sliding foundations, when the building is modeled as a mass with a spring, the mass of the grillage is not considered. In [7-9], the results of studies of the spatial structures of buildings on the action of real earthquakes using the LSDYNA software package are given. In many studies, when studying the motion of the material point on a rough plane, it is assumed that the material point is always subjected to the dry friction force against the motion, with multiple stops and slips not considered.

In nonlinear problems of seismodynamics of the underground structures, the model of the dry friction in the pipeline-soil interaction is used [12]. In [13], a finite-difference approximation of the equation of the motion of the rod with external dry friction was built, and an algorithm of the solution was constructed; later, this algorithm was used in [14-16]. In [17], vertical vibrations of the buildings with distributed and concentrated parameters are considered. In [18-20] seismodynamics of the underground pipelines under the harmonic and real impacts are numerically studied.

In this work, an algorithm similar to the one described in [13] will be used to calculate the buildings with sliding foundations under the action of the seismic waves of real earthquakes.

\section{Materials and methods of solution}

Let the horizontal and vertical motions of the building foundation be given as a seismogram of the real earthquake. Let us assume that the lower part of the building foundation acquires the same motions, and the upper part of the foundation or the grillage is separated by a twolayer fluoroplastic $[2,3]$. As a model of the interaction of the two fluoroplastic layers in the horizontal direction, we will take the Coulomb dry friction model; we will assume that they are absolutely rigidly connected in the vertical direction. In this formulation of the problem, the ground deformation is not considered; it is considered a rigid fixed of the lower foundation with the base soil.

The calculation scheme of the multi-storey building considering seismic isolation with dry friction according to the normative document takes the following form (figure 1). 

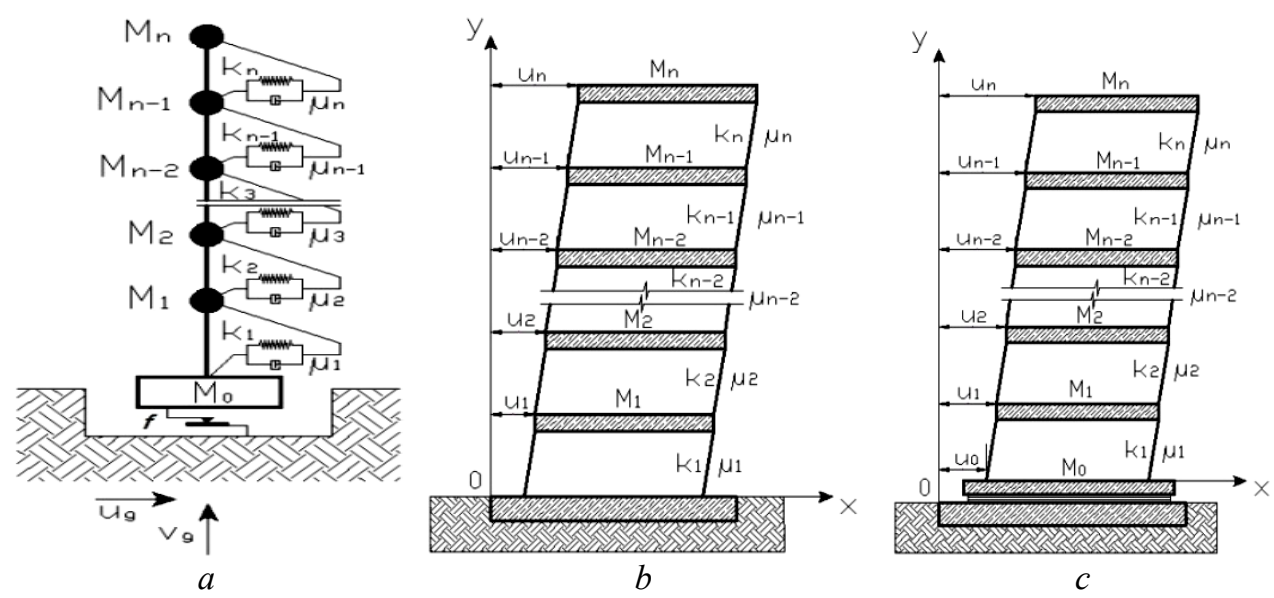

Fig. 1. Cantilever calculation scheme in the form of the elastic rod with concentrated masses $(a)$, calculation scheme of the multi-storey building in the plane with a rigid base collar $(b)$, and with seismic isolation $(c)$

The building is represented by a one-dimensional shear model with concentrated masses and inertialess elastic bonds

$$
\begin{aligned}
{[M] \cdot\{\ddot{U}\}+[C] \cdot\{\dot{U}\}+[K] \cdot\{U\}=\{Q(t)\} } \\
\{U\}=\left\{U U_{s t}\right\},\{\dot{U}\}=0, \text { at } t=0
\end{aligned}
$$

where $[M]$ is the diagonal matrix of masses, the masses are located at the floor levels, $[K]$ is the stiffness matrix, $[C]=\alpha \cdot[M]+\beta \cdot[K]$ is the viscosity matrix, $\{U\}=\left\{u_{0}, u_{1}, \ldots, u_{n}, v_{1}, \ldots, v_{n}\right\}^{T}$ is the displacement vector, $u_{i}, v_{i}$ are horizontal and vertical displacements of the masses, $\left\{U_{s t}\right\}$ is the displacement vector at the initial moment of time, the elements corresponding to the shear displacement are zero, and the vertical displacement is determined from the solution of the static problem. The condition for the interaction of the mass $M_{0}$ with the sliding lower foundation takes the following form

$$
\begin{gathered}
u_{0}=u_{g}-u_{r}, \text { if }\left|F_{0}\right|<\left|F_{f r}\right|, \text { i.e. when moving together, } \\
F_{0}=F_{f r}, \text { when slips, } \\
v_{0}=v_{g}
\end{gathered}
$$

where is $u_{0}, v_{0}$ is displacement of the grillage, $u_{g}, v_{g}$ are horizontal and vertical displacements of the lower part of the foundation, i.e., approximated functions of the digitized earthquake seismogram, $u_{r}$ is the displacement value at the time of the current joint movement of the lower part of the foundation and the movement of the grillage, i.e., the difference between the values of the displacements of the lower part of the foundation and of the grillage (at the initial moment of time $\left.u_{r}=0\right), F_{0}$ is the unknown value of the coupling force between the upper 
and lower foundations, $F_{f r}=\operatorname{sign}\left(\dot{u}_{g}-\dot{u}_{0}\right) \cdot f \cdot P$ is the value of the dry friction force, $f$ is the dry friction coefficient, $P$ is the pressure force on the sliding element of the foundation in the dynamic process, if the vertical vibrations are not considered, then it is the building weight.

It should be noted that the vertical vibrations are independent of the horizontal vibrations of the buildings and the horizontal vibrations are dependent on the vertical vibrations of the buildings through the condition (3), as the pressure on the sliding foundation changes during the vertical vibrations.

In the joint motion, the displacement $u_{0}$ is determined by equality (2), and the equation of the motion of the mass $M_{1}$ takes the following form

$$
M_{1} \ddot{u}_{1}+k_{1} u_{1}+c_{1} \dot{u}_{1}-k_{2}\left(u_{2}-u_{1}\right)-c_{2}\left(\dot{u}_{2}-\dot{u}_{1}\right)=k_{1} u_{0}+c_{1} \dot{u}_{0} .
$$

In this case $Q_{1}=k_{1} u_{0}+c_{1} \dot{u}_{0}$, the remaining elements of the vector $\{Q\}$, corresponding to the horizontal displacements of concentrated masses, are equal to zero. The equation of the vertical motion of the mass $M_{1}$ takes a form similar to (5), $M_{1} g$ added to the right side. The elements of the vector $\{Q\}$ corresponding to the vertical displacements of concentrated masses are equal to the values of weights of the corresponding concentrated masses.

Sliding with dry friction occurs only when condition (3) is fulfilled. The considered problem (1), (2), (3) is a nonlinear problem; there are no conditions for calculation of the unknown function $F_{0}$ and during the dynamic process, the dimensions of the matrixes $[M]$ and $[K]$. For sliding the equation for mass $M_{0}$

$$
M_{0} \cdot \ddot{u}_{0}-k_{1}\left(u_{1}-u_{0}\right)-c_{1}\left(\dot{u}_{1}-\dot{u}_{0}\right)=F_{f r} \text {, here with } Q_{0}=F_{f r} \text {. }
$$

We will use the following algorithm to solve the problem as a whole. At each time step, we solve the problem in three statements:

1. Equation (1) is solved with condition (2);

2. Equation (1) is solved with condition (3), at $F_{0}=f \cdot P$;

3. Equation (1) is solved with condition (3), at $F_{0}=-f \cdot P$.

The matrixes $[M]$ and $[K]$ in the first formulation are both sized $2 n \times 2 n$ (here, $n$ the number of the floors of the building), and in the second and third formulations $(2 n+1) \times 2 n$. The choice of the true solution from these three solutions is as follows. If relative velocities $\dot{u}_{g}-\dot{u}_{0}$ in the second and third solutions have different signs, then the true solution is the solution in the first formulation because the applied dry friction force makes a move in different directions and hence the unknown force is smaller than the limiting value of the dry friction force, i.e., the masses of the lower and upper foundations move together without sliding at this step in time. If relative velocities in the second and third problem statements have the same signs, then the true solution is the solution of the problem in the statement in which the relative velocity in absolute value is the smallest because the dry friction force is directed against the relative motion. All three problems are solved by the Newmark method [1]; the digitized earthquake seismogram is approximated by a linear function in the recording step interval when the time step of the approximation is smaller than the earthquake recording step. 


\section{Results and Discussion}

Let us discuss the results of the calculations using the following examples. Let the characteristics of the 4 and 9 storey buildings are given and the seismograms of the following earthquakes:

1. Cairano 3 - 000319 (16.01.1981, 8 MSK-64, maximum acceleration $-1.47 \mathrm{~m} / \mathrm{s}^{2}$, maximum displacement $-0.0029 \mathrm{~m}$, digitizing step - $0.005 \mathrm{~s}$, duration $-22.175 \mathrm{~s}$ );

2. Tolmezzo-Diga Ambiesta - 000055 (06.05.1976, 9 MSK-64, maximum acceleration $-3.35 \mathrm{~m} / \mathrm{s}^{2}$, maximum displacement $-0.0039 \mathrm{~m}$, digitizing step $-0.005 \mathrm{~s}$, duration - $46.535 \mathrm{~s}$ );

3. Nocera Umbra 2 - 000856 (03.04.1998, 9 MSK-64, maximum acceleration - 3.73 $\mathrm{m} / \mathrm{s}^{2}$, maximum displacement $-0.0054 \mathrm{~m}$, digitizing step - $0.005 \mathrm{~s}$, duration $-40.990 \mathrm{~s}$ ).

The four-story building of the series of 76-017SA/53 has the following characteristics: the masonry building with dimensions in the plan $389.88 \mathrm{~m}^{2}$; concentrated masses at the levels of the upper part of the foundation and floors $M_{0}=698000 \mathrm{~kg}, M_{1}=495000 \mathrm{~kg}$ , $M_{2}=495000 \mathrm{~kg}, M_{3}=495000 \mathrm{~kg}, M_{4}=497575 \mathrm{~kg}$, with the total weight of the building pressing on the lower part of the foundation equal $P=26269635 \mathrm{~N}$; shear stiffness of the floors is the same $k_{i}=16.08 \cdot 10^{8} \mathrm{~N} / \mathrm{m}$; viscosity of the building material of the floors is the same $\mu_{i}=26.9 \cdot 10^{5} \mathrm{Ns} / \mathrm{m}$. The values of natural vibration frequencies with rigid foundation embedding are $\omega_{1}=34 \mathrm{~Hz}, \omega_{2}=62 \mathrm{~Hz}, \omega_{3}=87 \mathrm{~Hz}, \omega_{4}=106 \mathrm{~Hz}$.

The nine-story building of the series of $76-017 \mathrm{SP} / 53$ has the following characteristics: the large-panel building with dimensions in plan $291.6 \mathrm{M}^{2}$; concentrated masses at the levels of the upper part of the foundation and floors $M_{0}=449000 \mathrm{~kg}$, $M_{1}=379500 \mathrm{~kg}, \quad M_{2}=379500 \mathrm{~kg}, \quad M_{3}=379500 \mathrm{~kg}, \quad M_{4}=379500 \mathrm{~kg}$, $M_{5}=379500 \mathrm{~kg}, \quad M_{6}=379500 \mathrm{~kg}, \quad M_{7}=379500 \mathrm{~kg}, \quad M_{8}=379500 \mathrm{~kg}$, $M_{9}=341000 \mathrm{~kg}$, with the total weight of the building pressing on the lower part of the foundation equal $P=37494800 \mathrm{~N}$; the shear stiffness of the floors is equal $k_{i}=32.357 \cdot 10^{9} \mathrm{~N} / \mathrm{m}$; the viscosity of the building material is equal $\mu_{i}=10.58 \cdot 10^{6} \mathrm{Ns} / \mathrm{m}$. The values of natural vibration frequencies with a rigid foundation are $\omega_{1}=79 \mathrm{~Hz}$, $\omega_{2}=160 \mathrm{~Hz}, \omega_{3}=239 \mathrm{~Hz}, \omega_{4}=314 \mathrm{~Hz}, \omega_{5}=380 \mathrm{~Hz}$.

In the numerical solution with dry friction problems, regardless of the choice of explicit or implicit finite-difference scheme, the time step must be chosen to ensure sufficient accuracy. In our example calculations, the time step was $0.0001 \mathrm{~s}$.

The results are shown below in the form of displacements and shear forces figures for the four-story and nine-story buildings.

Figure 2 shows the results of the calculations of the changing of displacements in time of the upper and lower parts of the foundation of the four-story building under the earthquake №1, taking into account the horizontal impact (a) and simultaneously the horizontal and vertical impacts (b) of the real earthquake records. The slip times from the beginning of the seismic wave impact process are equal to: $3.67 \mathrm{~s}$ (figure 2, a) and $3.01 \mathrm{~s}$ (figure $2, b$ ). The occurrence of the first slip is associated with a change in the direction of the motion of the lower foundation. The transition from sliding with dry friction to comotion and vice versa occurs many times, depending on the conditions discussed above. By the end of the process, the residual shear equals $0.0028 \mathrm{~m}$ for horizontal impact and 0.0019 $\mathrm{m}$ if vertical motion is considered. 


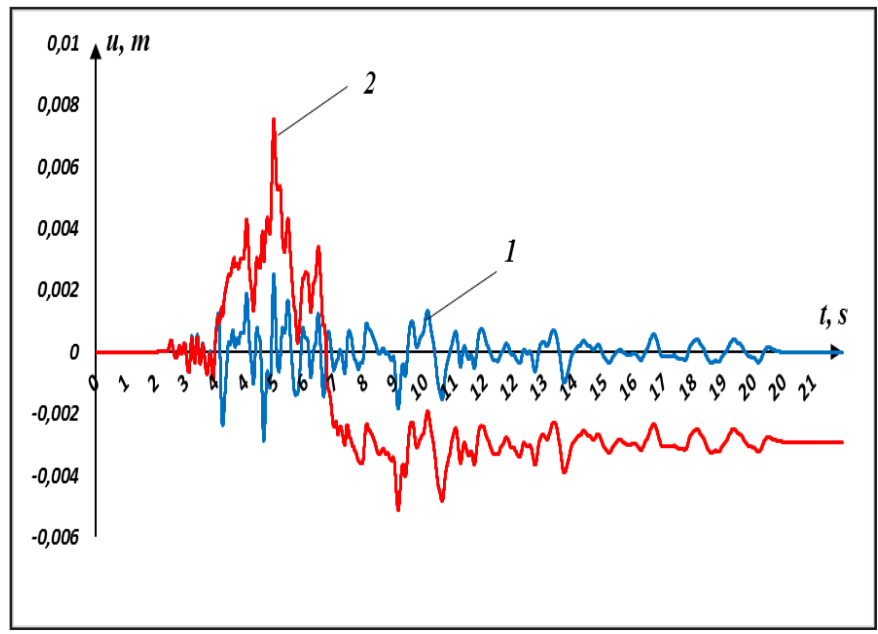

$a$

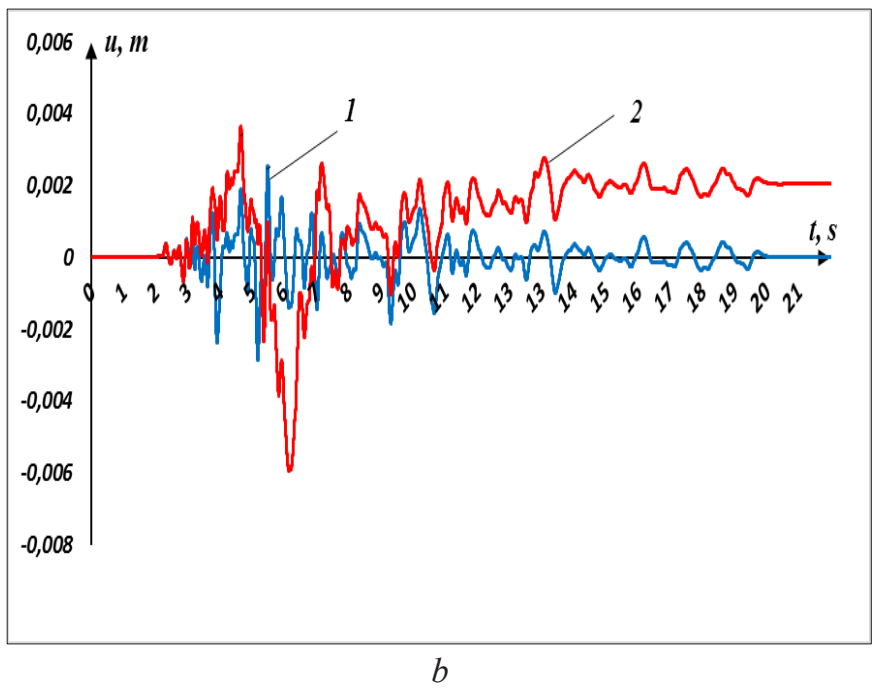

Fig. 2. Horizontal displacements of the lower (1) and upper (2) parts of the foundation over time of the four-story building taking into account the horizontal $(a)$ and simultaneous horizontal and vertical impact $(b)$ under the real earthquake records.

Figure 3 shows the results of the calculations of the changing of displacements in time of the upper and lower parts of the foundation of the nine-story building during earthquake №1, taking into account the horizontal impact (a) and simultaneously horizontal and vertical impacts (b) of real earthquake records. The slip time from the beginning of the seismic wave impact process is equal to: $2.49 \mathrm{~s}$ (figure 3, a) and $2.47 \mathrm{~s}$ (figure 3, b). The transition from slip with dry friction to co-motion and vice versa occurs many times, depending on the conditions discussed above. By the end of the process, the residual displacement is $0.0011 \mathrm{~m}$ for horizontal impact and $0.0014 \mathrm{~m}$ if vertical motion is considered. Figures 2 and 3 show the strong influence of the vertical impact on the horizontal oscillation process of the buildings. 


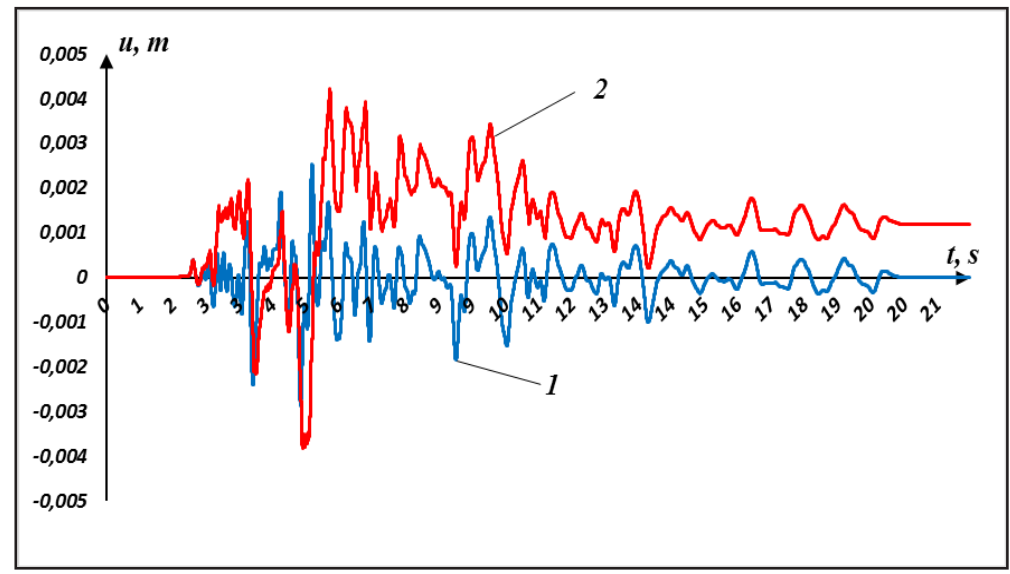

$a$

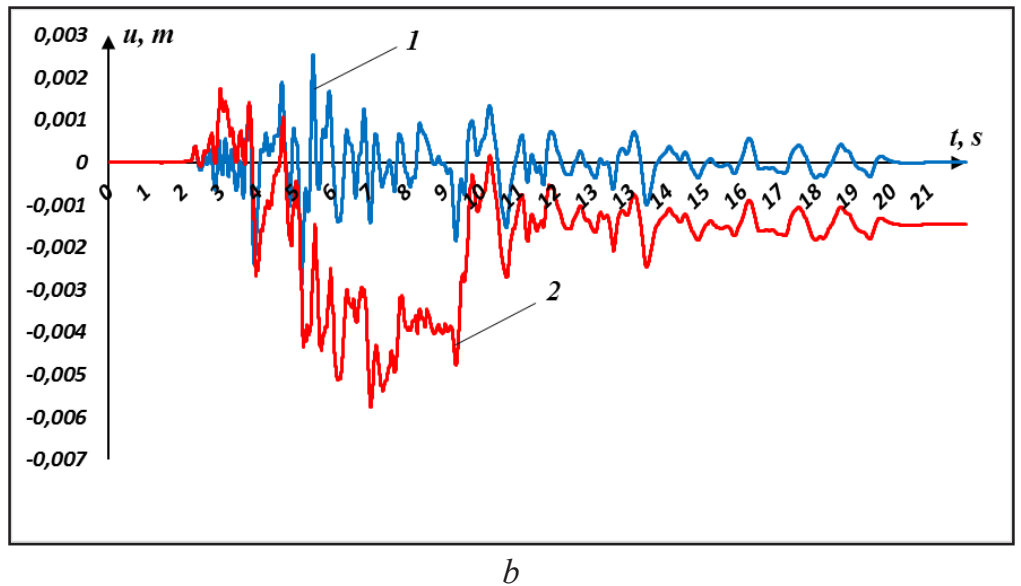

Fig. 3. Horizontal displacements of the lower (1) and upper (2) parts of the foundation over time of a nine-story building taking into account the horizontal (a) and simultaneous horizontal and vertical impact (b) under the real earthquake records.

Figures 4-5 show the calculation of the shear force variations with time in the ground floor of the four-storey and the nine-storey buildings during earthquake №1 for the cases without and with slip element. These figures show that the use of the sliding foundation with fluoroplastic with the dry friction coefficient $f=0.05$ leads to a reduction in of the maximum shear force value in 2.7 and 2.3 times to the case of without sliding foundation while accounting for vertical movement reduces by a factor in 6.4 and 5.4 times respectively for the four-storey and nine-storey buildings. 

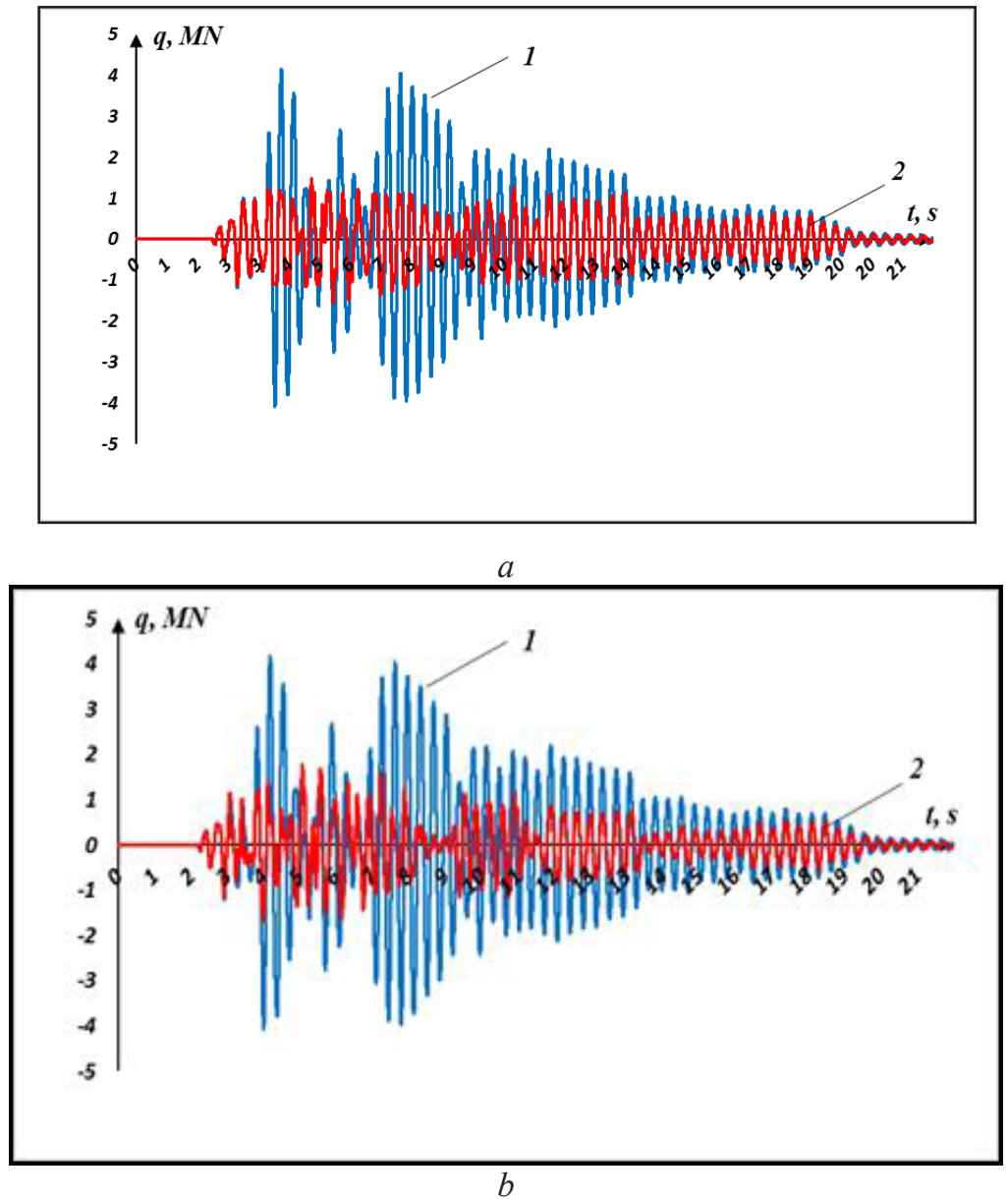

Fig. 4. Change in the shear force on the first floor of the four-story building without regard to slip (1) and with regard to slip (2) taking into account the horizontal (a) and simultaneous horizontal and vertical impact (b) under the real earthquake records.

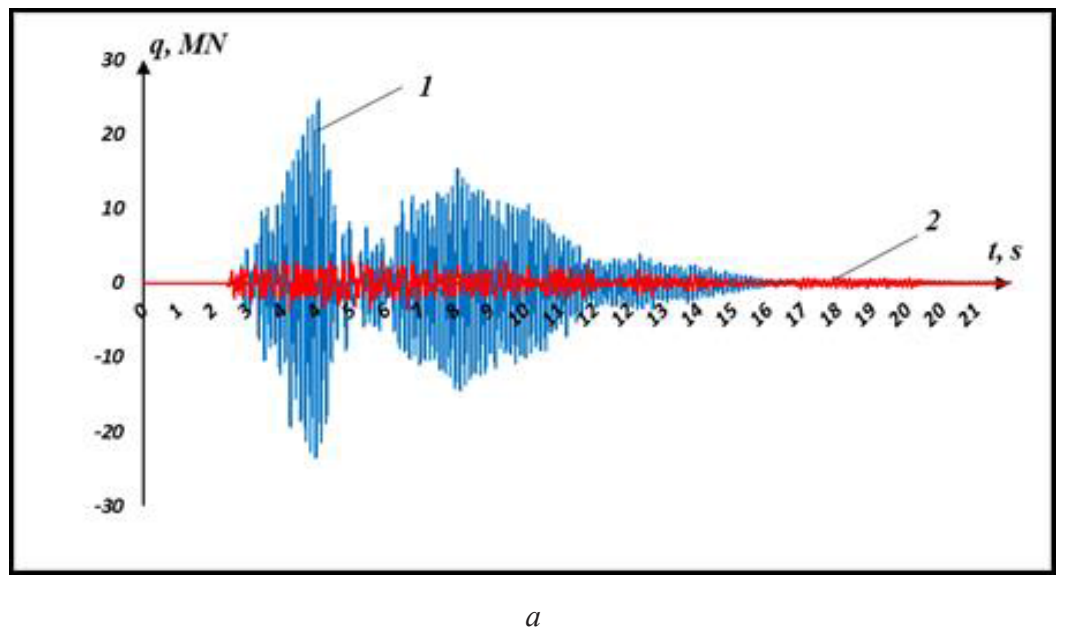




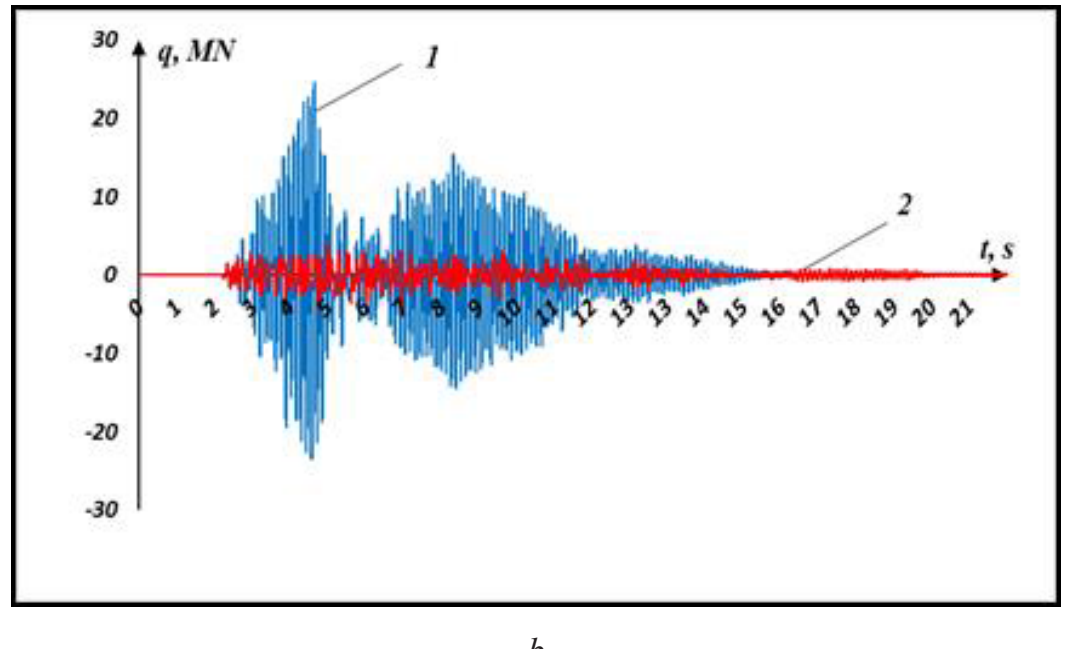

$b$

Fig. 5. Change in the shear force on the first floor of the nine-story building without regard to slip (1) and with regard to slip (2) taking into account the horizontal (a) and simultaneous horizontal and vertical impact (b) under the real earthquake records.

In [3], based on experimental results, it is written that fluoroplastic can reduce the load by up to four times. A computational experiment has shown that in some cases, fluoroplastic in the sliding foundation can reduce the maximum load from an earthquake by up to 9 times. Increasing the dry friction coefficient reduces the efficiency of the sliding foundation. For weak earthquakes, buildings do not feel the presence of the sliding foundation [11]. The vibrations of the buildings in earthquakes №2 and №3 are also strongly influenced by the vertical component of seismic impact.

In earthquake №2 decreases of the maximum shear force value by the factor of 8.9 and 1.1 times with respect to the case without sliding foundation, while accounting for the vertical motion decreased by the factor of 4.2 and 1.6 times respectively four-story and the nine-story buildings. In earthquake №3, the maximum shear value force decreases by a factor of 3.2 and 3.8 concerning the case of no sliding foundation, while accounting for vertical motion decreased by 3.0 and 3.5 times, respectively four-story and the nine-story buildings.

\section{Conclusions}

An algorithm for the numerical solution of the problem of the building's vibration with sliding foundations using the Coulomb dry friction model with consideration of slip stops under the simultaneous effect of horizontal and vertical components of the seismogram of the real earthquakes is presented. It is shown using the example of the four-story and the nine-story buildings based on the recordings of the three earthquakes that the use of a sliding foundation does not always lead to multiple reductions in the shear force the consideration of the vertical component of the seismogram significantly influences the shear vibration process of the building. When using the sliding foundation to reduce the effect of an earthquake, it is necessary, based on the construction site, to select seismogram records that are close in terms of the prevailing frequencies and to carry out calculations using the algorithm described above while simultaneously affecting the horizontal and vertical components of the seismogram. 


\section{References}

1. Chopra A.K. Dynamics of Structures: Theory and Applications to Earthquake Engineering 4th Edition (Prentice Hall, Englewood Cliffs, New Jersey), p. 994 (2012)

2. Kuznetsov V.D., and Chen S, Sliding belt with PTFE of an earthquake-proof building Civil Engineering Journal № 3 (2011)

3. Chen $\mathrm{S} 2011$ Seismically isolated building with sliding fluoroplastic belt $\mathrm{p} 86$

4. Bakre S V, Jangid R S and Reddy G R 2004 Seismic Response of Piping Systems with Isolation Devices 13th World Conference on Earthquake Engineering Vancouver № 2676

5. Sanjayo K.P. and Ravi S. Influence of Friction Models on Response Evaluation of Buildings with Sliding Isolation Devices 13th World Conference on Earthquake Engineering Vancouver № 1373, (2004)

6. Kentro N, Dai Shimazaki, Satoshi Yoshida and Ken Okada, Application of Seismic Isolation Systems in Japanese High-Rise Buildings CTBUH Journal 2 pp. 36-40, (2015)

7. Mkrtychev O.V. and Mingazova S.M. Study of the seismic isolation sliding belt: the case of a monolithic reinforced concrete building IOP Conf. Series: Journal of Physics: Conf. Series 1425012161 (2020), doi:10.1088/1742-6596/1425/1/012161

8. Mkrtychev O.V., and Mingazova S.M. Analysis of the reaction of reinforced concrete buildings with a varying number of stories with a seismic isolation sliding belt to an earthquake IOP Conf. Series: Materials Science and Engineering 869052065 (2020), doi:10.1088/1757-899X/869/5/052065

9. Mkrtychev O.V, and Bunov A.A., Calculation on displacements features of seismic isolated building Vestnik MGSU № 6 pp 63-70, (2014), doi:10.22227/19970935.2014.6.63-70

10. Yuvmitov A.S and Hakimov S.R. Study of the effect of the seismic islation on the dynamic performance of the building ACTA TTPU 2 pp. 59-65 (2020)

11. Lapin V.A., Erjonov S.E, and Daugavet V.P. Comparative analysis of the effect of seismic isolation using instrumental records of seismic engineering stations Problems of Mechanics, № 4, pp. 14-18 (2018)

12. Nikitin L.V. Statics and dynamics of solids with external dry friction, Mosk. Litsey, p. 261 (1998), doi:10.1007/978-3-642-60114-9_25

13. Mirzaev I.M. Dynamics of Prestressed Rods under Impact Loads Dynamic Problems of Inelastic Medium, Continuum Dynamics, Institute of Fluid Dynamics of the Siberian Branch of the Russian Academy of Sciences, 71 pp. 65-74, (1985)

14. Isakov A.L., and Shmelev V.V. Wave processes when driving metal pipes into the ground using shock-pulse generators Journal of Mining Science 34 pp 139-147, (1998), https://doi.org/10.1007/BF02803446

15. Smirnov A.L. Computation of the process of impact submersion of a pile in the ground Soviet Mining 25 pp 359-365, (1989), https://doi.org/10.1007/BF02528556

16. Aleksandrova N.I. Numerical-analytical studies into impact pipe driving in soil with dry friction Part I Nondeformable external medium Journal of Mining Science $\mathbf{4 8}$ pp. 856-869, (2012),

17. Mirzaev I.M. Reactions of composite structures, with concentrated and distributed parameters, to seismic action (vertical vibrations) Sov Min Sci 12(3), pp. 296-300, (1976), https://doi.org/10.1007/BF02594874

18. Bekmirzaev D., Mirzaev I., Mansurova N., Kosimov E, and Juraev D.P. Numerical methods in the study of seismic dynamics of underground pipelines IOP Conference Series: Materials Science and Engineering 869(5) 052035 (2020), https://doi.org/10.1088/1757-899X/869/5/052035 
19. Bekmirzaev D.A., and Mirzaev I. Earthquake Resistance Assessment of Buried Pipelines of Complex Configuration Based on Records of Real Earthquakes, Soil Mechanics and Foundation Engineering 57(6) pp. 491-496, (2021), doi: https://doi.org/10.1007/s11204-021-09697-0

20. Nishonov N., Bekmirzaev D., An E, Urazmukhamedova Z., and Turajonov K. Behaviour and Calculation of Polymer Pipelines Under Real Earthquake Records, IOP Conf. Ser. Mater. Sci. Eng. 869052076 (2020), doi:10.1088/1757-899X/869/5/052076 